\title{
Randomized Controlled Trial of Adjuvant Chemotherapy with Fluoropyrimidines Versus Surgery-alone for Gastric Cancer
}

\author{
JEONG HO MOON ${ }^{1}$, YOSHIYUKI FUJIWARA ${ }^{1,2}$, MOTOHIRO HIRAO ${ }^{3}$, HIROSHI IMAMURA ${ }^{4}$, \\ YUTAKA KIMURA $^{5}$, KAZUMASA FUJITANI ${ }^{6}$, JUNYA FUJITA ${ }^{7}$, SHIGEYUKI TAMURA ${ }^{8}$, \\ SHUJI TAKIGUCHI $^{9}$, MASAHIKO YANO $^{1}$, MASAKI MORI ${ }^{9}$ and YUICHIRO DOKI ${ }^{9}$ \\ ${ }^{1}$ Department of Surgery, Osaka Medical Center for Cancer and Cardiovascular Diseases, Osaka, Japan; \\ ${ }^{2}$ Division of Surgical Oncology, Department of Surgery, Faculty of Medicine, Tottori University, Tottori, Japan; \\ ${ }^{3}$ Department of Surgery, Osaka National Hospital, Osaka, Japan; \\ ${ }^{4}$ Department of Surgery, Toyonaka Municipal Hospital, Osaka, Japan; \\ ${ }^{5}$ Department of Surgery, Kindai University Hospital, Osaka, Japan; \\ ${ }^{6}$ Department of Surgery, Osaka General Medical Center, Osaka, Japan; \\ ${ }^{7}$ Department of Surgery, Sakai City Medical Center, Osaka, Japan; \\ ${ }^{8}$ Department of Surgery, Kansai Rosai Hospital, Hyogo, Japan; \\ ${ }^{9}$ Department of Gastroenterological Surgery, Osaka University Graduate School of Medicine, Osaka, Japan
}

\begin{abstract}
Aim: This prospective randomized study compared the survival of patients with stage IB-IIIA gastric cancer treated with surgery alone or surgery followed by adjuvant chemotherapy. Patients and Methods: Patients with pathological stage IB-IIIA disease were randomly assigned to the following groups: surgery alone $(n=116)$, or surgery followed by adjuvant chemotherapy with 5-fluorouracil, doxifluridine, or uracil-tegafur for 12 months (n=113). Results: The overall survival rate was $86.1 \%$ in the adjuvant group and $78.5 \%$ in the surgery-alone group. The overall survival rate did not significantly differ between the adjuvant-chemotherapy and surgery-only groups $(p=0.163)$. In the subgroup analyses, patients with stage II disease and those receiving uracil-tegafur treatment in the adjuvant group showed significantly better prognosis than those in the surgery-alone group $(p=0.036$ and 0.005 , respectively). Conclusion: This study did not find a significant survival benefit to be associated with adjuvant chemotherapy with fluoropyrimidines in patients with stage IBIIIA gastric cancer. However, it may be effective for patients with stage II disease. Additionally, uracil-tegafur is a promising agent for adjuvant chemotherapy of gastric cancer if $S-1$ is not available because of its toxicity.
\end{abstract}

Correspondence to: Yoshiyuki Fujiwara, MD, Division of Surgical Oncology, Department of Surgery, Faculty of Medicine, Tottori University, Tottori, Japan. Tel: +81 859386567, Fax: +81 859386569, e-mail: y-fujiwara@med.tottori-u.ac.jp

Key Words: Gastric cancer, adjuvant chemotherapy, fluoropyrimidine, 5-FU, 5'-DFUR, UFT.
Gastric cancer is the fifth most common malignancy and the third leading cause of cancer-related death worldwide (1). The only curative treatment for advanced gastric cancer is radical gastrectomy with regional lymph node dissection. In Japan, gastrectomy with extended lymph node dissection (D2) is considered the optimal treatment (2). Recently, several reports have shown the efficacy of gastrectomy with D2 $(3,4)$ and this was recommended for the treatment of gastric cancer in Europe and the US $(5,6)$. However, advanced gastric cancer recurrence rates are still high $(40-80 \%)(7,8)$ and adjuvant chemotherapy has been proposed even after curative resection to improve patient survival. Meta-analyses have shown that adjuvant chemotherapy is effective and provides a significant survival benefit for patients with advanced gastric cancer (9-14).

Fluoropyrimidine is a key chemotherapeutic drug for treatment of unresectable and recurrent gastric cancer (1521 ). Recent trials have shown that these drugs are effective as adjuvant chemotherapies for curative gastrectomy in patients with locally advanced gastric cancer. Postoperative adjuvant chemotherapy with uracil-tegafur (UFT) in patients with serosa-negative, node-positive gastric cancer prolonged overall and relapse-free survival (22). Subsequently, postoperative adjuvant chemotherapy with S-1 for patients with stage II or III gastric cancer diagnosed with the Japanese classification (23) who underwent gastrectomy plus D2 prolonged overall and relapse-free survival (24). Consequently, adjuvant chemotherapy with S-1 for gastric cancer stages II, IIIA, or IIIB is considered standard treatment in Japan. However, some patients treated with S-1 as an adjuvant chemotherapy cannot continue this treatment 
because of the severe adverse effects of S-1. As S-1 was designed to achieve higher concentrations of 5-fluorouracil (5-FU) in the blood owing to the combination of 5-chloro2,4-dihydroxypyridine and inhibition of 5-FU degradation, adverse effects occur more often and are more severe than those of other oral fluoropyrimidines (25). Furthermore, issues regarding the necessity for adjuvant chemotherapy for other stages and the effectiveness of adjuvant chemotherapy using other fluoropyrimidines are controversial. In the present study, we examined the efficacy of adjuvant chemotherapy with other fluoropyrimidines [5-FU, doxifluridine (5'-DFUR) and UFT] instead of the standard S-1 after curative surgery for patients with gastric cancer with stage IB, II, and IIIA disease.

\section{Patients and Methods}

Participants and study design. The following eligibility criteria were utilized for selecting patients: (i) histologically proven adenocarcinoma of the stomach; (ii) curative gastrectomy with R0 resection; (iii) pathological stage IB, II, or III gastric cancer; (iv) negative peritoneal lavage cytology during an operation; (v) under 75 years old; (vi) no therapy for gastric cancer before surgery and (vii) adequate organ function [leucocyte count $>4,000$ per $\mathrm{mm}^{3}$, platelet count $>100,000$ per $\mathrm{mm}^{3}$, hemoglobin count $>10 \mathrm{~g} / \mathrm{dl}$, aspartate (AST) and alanine (ALT) aminotransferase levels $<1.25$ times the upper limit of normal (ULN) at the center performing the test, total bilirubin concentration $<1.25$ times the ULN, blood urea nitrogen level $<1.25$-times the ULN, and creatinine concentration level $<1.25$-times the ULN]. Written informed consent was obtained from all patients after approval of the Institutional Review Board at each participating center (No. 240). The stage classification and evaluation of resected specimens were performed in accordance with the guidelines of the Japanese Gastric Cancer Association (23).

The eligible patients with stage IB, II, or III gastric cancer who had undergone curative gastrectomy with R0 resection (23) were randomly assigned to surgery only or adjuvant chemotherapy groups within 6 weeks after surgery. These groups were assigned for treatment with the following fluoropyrimidines: (i) 5-FU, (ii) 5'DFUR, or (iii). UFT. The surgery-only patients of each drug group received no anticancer treatment after surgery, unless there was a confirmed relapse. Within 6 weeks after surgery, patients allocated to the adjuvant 5-FU group received an oral daily dose of $150 \mathrm{mg}$ 5 -FU for patients weighing $\leq 50 \mathrm{~kg}$ or $200 \mathrm{mg}$ for patients weighing $>50 \mathrm{~kg}$ every day for 12 months. The 5'-DFUR group received an oral daily dose of $600 \mathrm{mg}$ for patients weighing $\leq 50 \mathrm{~kg}$ or $800 \mathrm{mg}$ for patients weighing $>50 \mathrm{~kg}$ every day for 12 months. The UFT group received an oral daily dose of $300 \mathrm{mg}$ for patients with a body surface area $\leq 1.3 \mathrm{~m}^{2}$ or $400 \mathrm{mg} /$ body for patients with a body surface area $>1.3 \mathrm{~m}^{2}$ every day for 12 months.

Statistical analysis. The primary endpoint was overall survival. The secondary endpoints were relapse-free survival, site of relapse, and relapse rate. Additionally, we compared the effectiveness of each adjuvant chemotherapy drug. All data were analyzed with a statistical software package (JMP version 12.2.0; SAS Institute, Cary, NC, USA). Overall and relapse-free survival rates were calculated using the Kaplan-Meier method and were compared with
Table I. Characteristics of the 229 patients enrolled in this study.

\begin{tabular}{lcc}
\hline & $\begin{array}{c}\text { Adjuvant chemotherapy } \\
(\mathrm{n}=113)\end{array}$ & $\begin{array}{c}\text { Surgery only } \\
(\mathrm{n}=116)\end{array}$ \\
\hline $\begin{array}{l}\text { Gender ratio (male:female), } \mathrm{n} \\
\text { Median age (range), years }\end{array}$ & 88 (36-77) & $84(34-79)$ \\
Pathological tumor stage, $\mathrm{n}^{*}$ & & \\
T1 & 17 & 14 \\
T2 & 78 & 82 \\
T3 & 17 & 20 \\
T4 & 1 & 0 \\
Pathological nodal stage, $\mathrm{n}^{*}$ & & \\
N0 & 49 & 48 \\
N1 & 50 & 53 \\
N2 & 14 & 15 \\
Pathological stage, $\mathrm{n} *$ & & \\
Ib & 49 & 54 \\
II & 47 & 37 \\
IIIa & 17 & 25 \\
Type of gastrectomy, $\mathrm{n}$ & & \\
Total & 36 & 38 \\
Distal & 78 & 74 \\
Proximal & 2 & 5 \\
Other & 2 & 0 \\
Curability, n & & 70 \\
A & 82 & 34 \\
B & 43 & \\
\hline
\end{tabular}

*Japanese Classification of Gastric Carcinoma-Second English Edition.

a log-rank test among the surgery alone and adjuvant chemotherapy after surgery groups. Hazard ratios (HRs) were calculated by Cox regression analysis. The chi-square test was used to compare the relapse data between two groups. A $p$-value of less than 0.05 was considered statistically significant.

\section{Results}

Study profile. Between June 1997 and December 2003, 238 patients were randomly assigned to either the adjuvant chemotherapy or surgery-only groups. One hundred and twenty patients were randomized to the adjuvant chemotherapy group and 118 to the surgery-only group. After randomization, nine patients were found to be ineligible and excluded because three were assessed as having pathological stage I disease, five were more advanced stages, and one had ALT levels above the eligible criterion. Finally, 229 patients were included for analysis: 113 patients in the adjuvant chemotherapy group and 116 patients in the surgery-only group (Figure 1). Subsequently, patients in each group were reassigned to 5-FU or 5'-DFUR or UFT groups to confirm the efficacy of adjuvant chemotherapy for each drug. In the 5-FU group, 31 patients were in the adjuvant chemotherapy group and 40 patients were in the surgery-only group. In the UFT group, 40 patients were in the adjuvant chemotherapy group and 36 patients were in the surgery only 


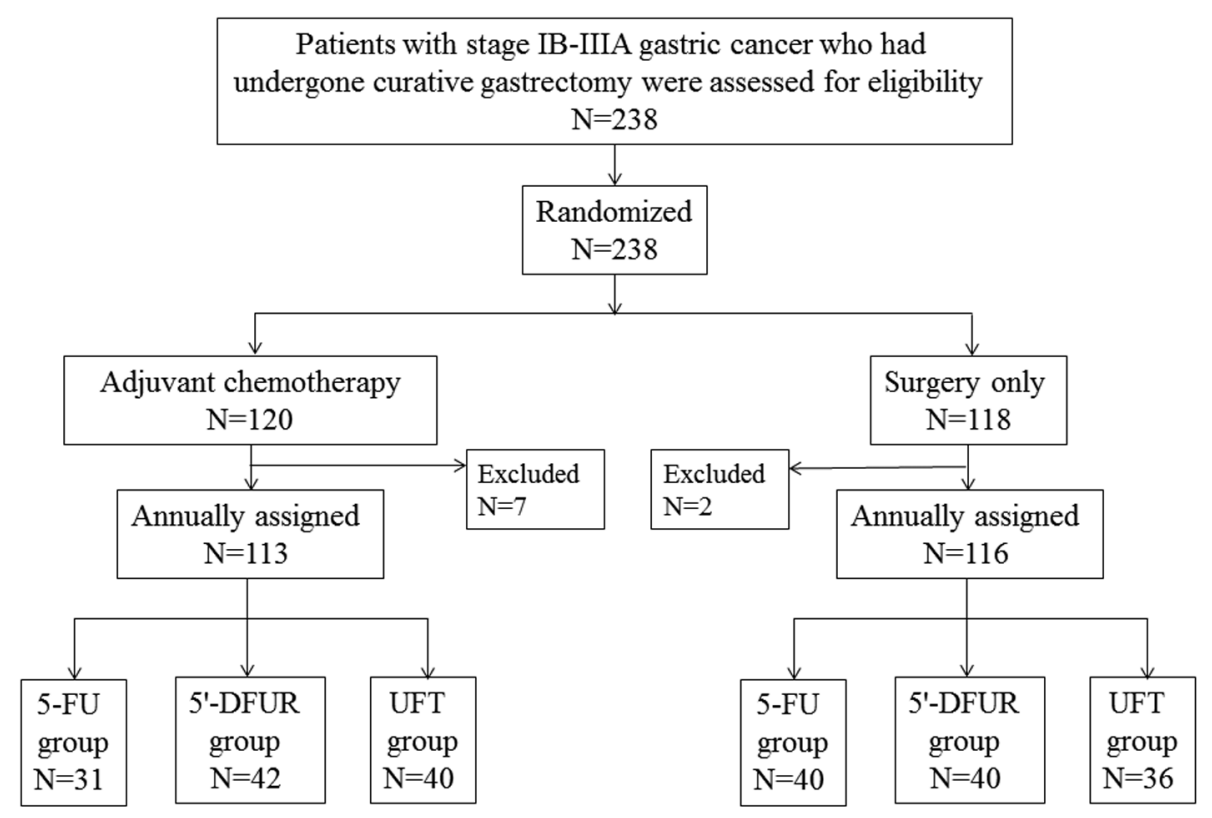

Figure 1. CONSORT flow chart. 5-FU: 5-Fluorouracil, 5'-DFUR: doxifluridine, UFT: uracil-tegafur.

group. In the 5'-DFUR group, 42 were in the adjuvant chemotherapy group and 40 patients were in the surgery only group. The clinical characteristics were similar between the adjuvant chemotherapy and surgery only groups (Table I).

Adverse events. The patients in the adjuvant chemotherapy group were evaluated for adverse events and treatment compliance. Sixteen patients $(51.6 \%)$ completed the one-year protocol in the 5-FU group, 21 patients $(52.5 \%)$ in the UFT group and 19 patients $(45.2 \%)$ in the 5 '-DFUR group. In the 5 -FU group, four patients $(12.9 \%)$ were withdrawn from treatment because of adverse events, two patients $(6.5 \%)$ because of recurrence and five patients $(16.1 \%)$ because of patient refusal. In the UFT group, seven patients (17.5\%) were withdrawn from treatment because of adverse events, two patients $(5.0 \%)$ because of recurrence and four patients $(10.0 \%)$ because of patient refusal. In the 5'-DFUR group, seven patients $(16.7 \%)$ were withdrawn from treatment because of adverse events, one patient $(2.4 \%)$ because of recurrence and eight patients $(19.0 \%)$ because of patient refusal. In the adjuvant-chemotherapy groups, adverse events, including gastrointestinal disorder, nausea, diarrhea, anorexia, gastrointestinal hemorrhage, dyspnea, malaise and hand-foot syndrome, were observed in eight patients treated with 5-FU (Table II). In the UFT group, six patients suffered from hepatic dysfunction, two displayed leukocytopenia and diarrhea, and one patient had urticaria. In the 5'-DFUR group, there were four patients suffering from gastrointestinal disorders and 6 patients with hepatic
Table II. Adverse events.

\begin{tabular}{lccc}
\hline & $\begin{array}{c}5-F U \\
(\mathrm{n}=31)\end{array}$ & $\begin{array}{c}\text { UFT } \\
(\mathrm{n}=40)\end{array}$ & $\begin{array}{c}5 ' \text {-DFUR } \\
(\mathrm{n}=42)\end{array}$ \\
\hline All events, $\mathrm{n}$ & $8(25.8 \%)$ & $11(27.5 \%)$ & $10(23.8 \%)$ \\
Gastrointestinal disorder & 1 & 0 & 4 \\
Nausea & 1 & 0 & 0 \\
Diarrhea & 1 & 2 & 0 \\
Anorexia & 1 & 0 & 1 \\
Gastrointestinal hemorrhage & 1 & 0 & 1 \\
Dyspnea & 1 & 0 & 0 \\
Fatigue & 1 & 0 & 0 \\
Malaise & 0 & 0 & 0 \\
Hepatic dysfunction & 0 & 6 & 1 \\
Leukocytopenia & 0 & 2 & 1 \\
Dizziness & 0 & 0 & 1 \\
Urticaria & 0 & 1 & 0 \\
Pruritus & 0 & 0 & 1 \\
Hand-foot syndrome & 1 & 0 & 0 \\
\hline
\end{tabular}

5-FU: 5-Fluorouracil; UFT: uracil-tegafur; 5'-DFUR: doxifluridine.

dysfunction, dizziness, pruritus, gastrointestinal hemorrhage, leukocytopenia and anorexia.

Survival analyses. The median follow-up period was 5.5 years. Twenty patients died in the adjuvant chemotherapy group and 26 patients died in the surgery-only group. The causes of death were disease-specific in 15 patients and due 
A



B

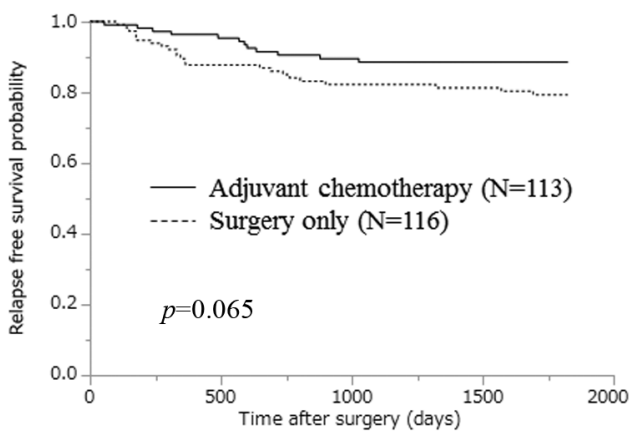

Figure 2. Overall (A) and relapse-free (B) survival for all 299 patients. $p$-Values from log-rank test.
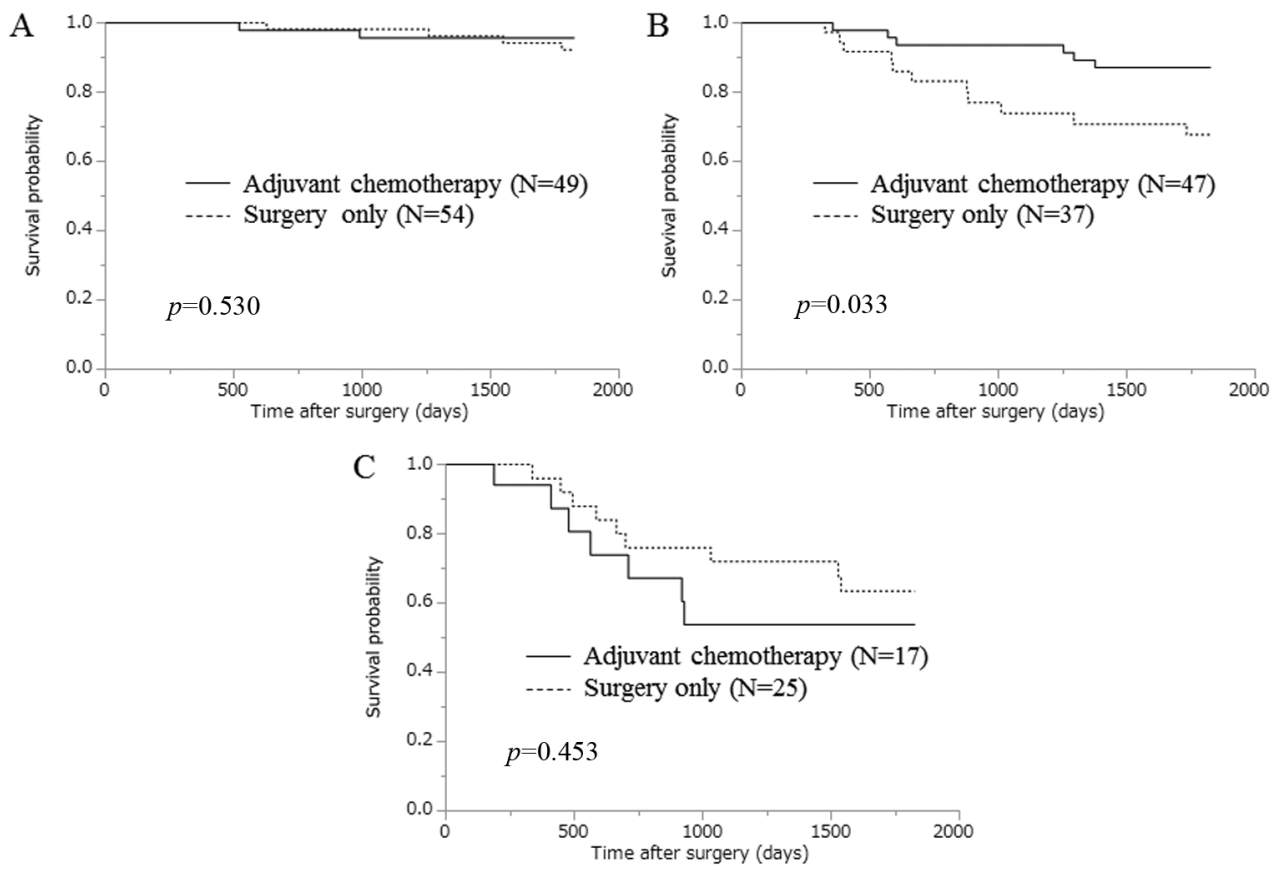

Figure 3. Overall survival for patients with stage IB (A), stage II (B) and stage IIIA (C) gastric cancer. p-Values from log-rank test.

to other reasons in five in the adjuvant chemotherapy group. Cancer-related death was observed in 20 patients and death attributable to other causes was observed in five patients in the surgery-only group. The 5-year overall survival rate was $86.1 \%$ for the adjuvant chemotherapy group and $78.5 \%$ for the surgery-only group. The overall survival rate did not significantly differ between the adjuvant chemotherapy and surgery-only groups $(\mathrm{HR}=0.64,95 \% \mathrm{CI}=0.33-1.20, p=0.163)$ (Figure 2A). The 5-year relapse-free survival rate was $88.6 \%$ for the adjuvant chemotherapy group and $79.3 \%$ for the surgery-only group. The relapse-free survival rate did not significantly differ between the adjuvant chemotherapy and surgery-only groups $(\mathrm{HR}=0.52,95 \% \mathrm{CI}=0.25-1.04, p=0.063)$ (Figure 2B). In subgroup analyses, overall survival was analyzed according to the pathological stage and the drug used for adjuvant chemotherapy (Figures 3 and 4). The overall survival of patients with pathological stage IB or III showed no significant difference between the adjuvantchemotherapy and surgery-only groups. By contrast, the overall survival of patients with pathological stage II disease was significantly better in the adjuvant-chemotherapy group than that in the surgery-only group $(\mathrm{HR}=0.36,95 \% \mathrm{CI}=0.12$ - 

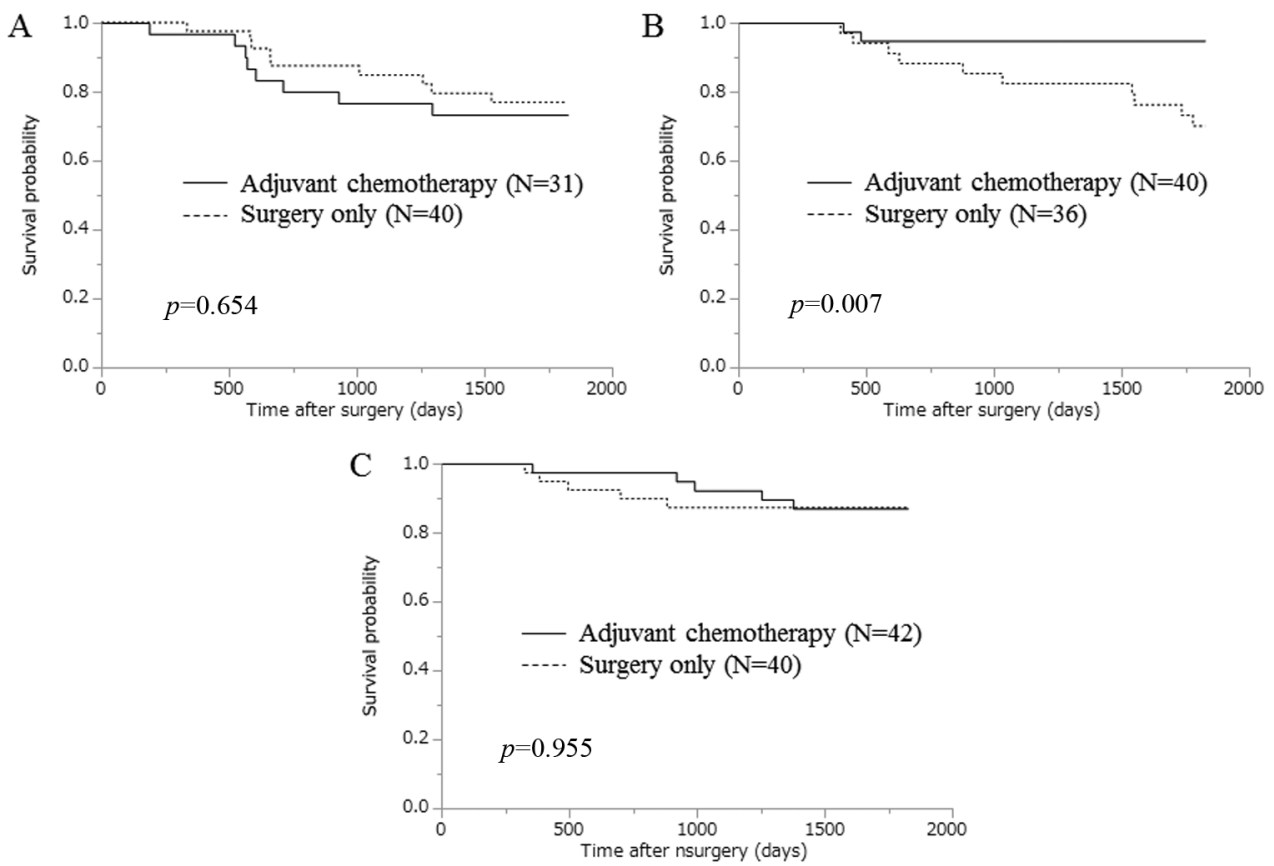

Figure 4. Overall survival in patients treated with 5-fluorouracil (A), uracil-tegafur. (B) and doxifluridine (C). p-Values from log-rank test.

0.94, $p=0.036$; log-rank $p=0.033$ ). In comparison of the drugs used for adjuvant chemotherapy, the 5-FU and 5'DFUR groups showed no significant differences in overall survival between the adjuvant-chemotherapy and surgeryonly groups. By contrast, overall survival for the UFT group was significantly better for the adjuvant-chemotherapy group than that for the surgery-only group $(\mathrm{HR}=0.16,95 \%$ $\mathrm{CI}=0.02-0.61, p=0.005 ; \log$ rank $p=0.007)$. Seventeen patients $(15.0 \%)$ had recurrent disease in the adjuvant chemotherapy group compared with 25 patients $(21.6 \%)$ in the surgery-only group. The most common site of recurrence was in the liver (18 patients), followed by the peritoneum (12 patients). Recurrence in the liver was found to have a significantly lower incidence in the chemotherapy group than that in the surgery-only group (Table III).

\section{Discussion}

In this randomized study, we did not demonstrate survival benefits for adjuvant chemotherapy with fluoropyrimidines in patients with stage IB or II or IIIA gastric cancer after curative surgery. However, in the subgroup analysis, the overall survival of patients with stage II disease treated with adjuvant chemotherapy was significantly better than in those treated with surgery alone: the 5-year overall survival rates were $87.1 \%$ and $67.7 \%$, respectively. Among patients with stage III disease, the results from this trial did not
Table III. First site of recurrence.

\begin{tabular}{lccc}
\hline Site & $\begin{array}{c}\text { Adjuvant } \\
\text { chemotherapy, } \mathrm{n} \\
\mathrm{n}=113\end{array}$ & $\begin{array}{c}\text { Surgery } \\
\text { only, } \mathrm{n} \\
\mathrm{n}=116\end{array}$ & $p$-Value \\
\hline Peritoneal & $5(4.4 \%)$ & $7(6.0 \%)$ & 0.769 \\
Liver & $4(3.5 \%)$ & $14(12.1 \%)$ & 0.025 \\
Distant lymph nodes & $4(3.5 \%)$ & $4(3.4 \%)$ & $>0.999$ \\
Local & $1(0.9 \%)$ & $1(0.9 \%)$ & $>0.999$ \\
Other & $1(0.9 \%)$ & $1(0.9 \%)$ & $>0.999$ \\
Unknown & $4(3.5 \%)$ & $1(0.9 \%)$ & 0.37 \\
Total number of & $17(15.0 \%)$ & $25(21.6 \%)$ & 0.234 \\
recurrent cases & & & \\
\hline
\end{tabular}

demonstrate benefits for adjuvant chemotherapy with respect to overall survival. The ACTS-GC and CLASSIC trials recently reported that postoperative adjuvant chemotherapy with S-1 or capecitabine plus oxaliplatin after D2 gastrectomy prolonged overall survival, including that of patients with stage III disease $(24,26,27)$. These results indicate that more powerful regimens are necessary for adjuvant chemotherapy to improve survival in patients with more advanced disease, such as those with stage III disease. In other subgroup analyses, the overall survival of the UFT group was significantly better in the adjuvant chemotherapy 
group than that in the surgery-alone group. The 5-year overall survival rate was $94.9 \%$ in the adjuvant chemotherapy group and $70.3 \%$ in the surgery-alone group. The N-SAS-GC trial showed similar results, with $86 \%$ for the adjuvant group with UFT and $73 \%$ for surgery alone in stage II and III patients with gastric cancer (22). Compared to the patients treated with surgery alone $(n=116)$ in our trial, although 5-FU and 5'-DFUR did not show survival benefits, for the UFT group $(n=40)$ overall survival was significantly better in the adjuvant chemotherapy group than that in patients treated with surgery alone $(\mathrm{HR}=0.23,95 \% \mathrm{CI}=0.04$ $0.76, p=0.013$; log-rank $p=0.027)$. The decreased liver metastasis in patients treated with adjuvant chemotherapy cannot be attributed to a worse-than-expected outcome in the surgery-only group because there was a $12.1 \%$ hematogenous metastatic rate among patients treated with surgery alone in our study, which was similar to those of other relevant studies $(14.7 \%$ in N-SAS-GC and $11.3 \%$ in ACTS-GC) $(22,24)$. Although these trials had a significantly lower incidence of distant lymph node metastasis in the adjuvant chemotherapy group than that in the surgery-alone group, our trial did not show a significant benefit in lymph node recurrence as only one case was observed in both the adjuvant-chemotherapy and surgery-alone groups.

The eligibility criteria for the N-SAS-GC and ACTS-GC trials excluded patients with $\mathrm{T} 1$ gastric cancer, and the CLASSIC trial included T1-staged patients, although there were only 11 (3\% of total patients) enrolled in the study. By contrast, in our trial, 31 patients with $\mathrm{T} 1$ tumors were included, which was $13.5 \%$ of the total cases enrolled. Although adjuvant chemotherapy with capecitabine plus oxaliplatin significantly prolonged overall survival, the toxicity of the combination chemotherapy was also prominent in the CLASSIC trial. Adverse events of all grades were present in $99 \%$ of all cases and grade 3 and 4 adverse events were present in $56 \%$ (27). Consequently, 33\% (174 out of 520 ) of patients withdrew from the active adjuvant chemotherapy in this trial. In the ACTS-GC trial, similar numbers of patients also withdrew from S-1 treatment (34\%, 177 out of 517 ). However, only $14 \%$ (17 out of 120 ) of patients withdrew from the adjuvant chemotherapy. These results indicate that adjuvant chemotherapy with other oral fluoropyrimidines instead of S-1 results in better compliance.

There are several potential limitations of this study, such as the limited number of patients and the three different types of oral fluoropyrimidines used for adjuvant chemotherapy. For these reasons, this study did not demonstrate advantages for fluoropyrimidine adjuvant chemotherapy. In 2007, the ACTS-GC trial demonstrated that S-1 was an effective adjuvant chemotherapy for patients with stage II and III gastric cancer after curative surgery. Currently, S- 1 treatment is a standard therapy for stage II and III disease. In conclusion, this study did not show significant benefits for postoperative adjuvant chemotherapy with fluoropyrimidine in patients with stage IB-IIIA gastric cancer after curative surgery. However, it may be effective for those with stage II disease. Among the tested drugs, UFT is a promising agent for gastric cancer adjuvant chemotherapy if S-1 is not available because of its toxicity.

\section{References}

1 Ferlay J, Soerjomataram I, Dikshit R, Eser S, Mathers C, Rebelo M, Parkin DM, Forman D and Bray F: Cancer incidence and mortality worldwide: sources, methods and major patterns in GLOBOCAN 2012. Int J Cancer 136: E359-386, 2015.

2 Japanese Gastric Cancer Treatment Guidelines 2010 (ver. 3). Gastric Cancer 14: 113-123, 2011.

3 Songun I, Putter H, Kranenbarg EM, Sasako M and van de Velde CJ: Surgical treatment of gastric cancer: 15-year follow-up results of the randomised nationwide Dutch D1D2 trial. Lancet Oncol 11: 439-449, 2010.

4 Wu C-W, Hsiung CA, Lo S-S, Hsieh M-C, Chen J-H, Li AF-Y, Lui W-Y and Whang-Peng J: Nodal dissection for patients with gastric cancer: a randomised controlled trial. Lancet Oncol 7: 309-315, 2006.

5 Ajani JA, Bentrem DJ, Besh S, D’Amico TA, Das P, Denlinger C, Fakih MG, Fuchs CS, Gerdes H, Glasgow RE, Hayman JA, Hofstetter WL, Ilson DH, Keswani RN, Kleinberg LR, Korn WM, Lockhart AC, Meredith K, Mulcahy MF, Orringer MB, Posey JA, Sasson AR, Scott WJ, Strong VE, Varghese TK Jr., Warren G, Washington MK, Willett C, Wright CD, McMillian NR and Sundar H: Gastric cancer, version 2.2013: featured updates to the NCCN Guidelines. J Natl Comprehen Cancer Netw 11: 531-546, 2013.

6 Waddell T, Verheij M, Allum W, Cunningham D, Cervantes A, Arnold D, European Society of Surgical Oncology (ESSO), European Society of Radiotherapy and Oncology (ESTRO): Gastric cancer: ESMO-ESSO-ESTRO Clinical Practice Guidelines for diagnosis, treatment and follow-up. Eur J Surg Oncol 40: 584-591, 2014.

7 Gallo A and Cha C: Updates on esophageal and gastric cancers. World J Gastroenterol 12: 3237-3242, 2006.

8 Gunderson LL: Gastric cancer - patterns of relapse after surgical resection. Semin Radiat Oncol 12: 150-161, 2002.

9 Earle CC and Maroun JA: Adjuvant chemotherapy after curative resection for gastric cancer in non-Asian patients: revisiting a meta-analysis of randomised trials. Eur J Cancer 35: 1059-1064, 1999.

10 Hermans J, Bonenkamp JJ, Boon MC, Bunt AM, Ohyama S, Sasako M and Van de Velde CJ: Adjuvant therapy after curative resection for gastric cancer: meta-analysis of randomized trials. J Clin Oncol 11: 1441-1447, 1993.

11 Janunger KG, Hafstrom L, Nygren P and Glimelius B: A systematic overview of chemotherapy effects in gastric cancer. Acta Oncol 40: 309-326, 2001.

12 Mari E, Floriani I, Tinazzi A, Buda A, Belfiglio M, Valentini M, Cascinu S, Barni S, Labianca R and Torri V: Efficacy of adjuvant chemotherapy after curative resection for gastric cancer: a meta-analysis of published randomised trials. A study of the GISCAD (Gruppo Italiano per lo Studio dei Carcinomi dell'Apparato Digerente). Ann Oncol 11: 837-843, 2000. 
13 Panzini I, Gianni L, Fattori PP, Tassinari D, Imola M, Fabbri P, Arcangeli V, Drudi G, Canuti D, Fochessati F and Ravaioli A: Adjuvant chemotherapy in gastric cancer: a meta-analysis of randomized trials and a comparison with previous metaanalyses. Tumori 88: 21-27, 2002.

14 Pignon JP, Ducreux M and Rougier P: Meta-analysis of adjuvant chemotherapy in gastric cancer: a critical reappraisal. J Clin Oncol 12: 877-878, 1994.

15 Boku N, Yamamoto S, Fukuda H, Shirao K, Doi T, Sawaki A, Koizumi W, Saito H, Yamaguchi K, Takiuchi H, Nasu J and Ohtsu A: Fluorouracil versus combination of irinotecan plus cisplatin versus S-1 in metastatic gastric cancer: a randomised phase 3 study. Lancet Oncol 10: 1063-1069, 2009.

16 Chang HM, Jung KH, Kim TY, Kim WS, Yang HK, Lee KU, Choe KJ, Heo DS, Bang YJ and Kim NK: A phase III randomized trial of 5-fluorouracil, doxorubicin, and mitomycin $\mathrm{C}$ versus 5-fluorouracil and mitomycin $\mathrm{C}$ versus 5 -fluorouracil alone in curatively resected gastric cancer. Ann Oncol 13: 17791785, 2002.

17 Cunningham D, Allum WH, Stenning SP, Thompson JN, Van de Velde CJ, Nicolson M, Scarffe JH, Lofts FJ, Falk SJ, Iveson TJ, Smith DB, Langley RE, Verma M, Weeden S, Chua YJ and Participants MT: Perioperative chemotherapy versus surgery alone for resectable gastroesophageal cancer. N Engl J Med 355: 11-20, 2006.

18 Koizumi W, Kurihara M, Sasai T, Yoshida S, Morise K, Imamura A, Akazawa S, Betsuyaku T, Ohkubo S, Takahashi H, Akiya T, Hamada T and Kiyohashi A: A phase II study of combination therapy with 5'-deoxy-5-fluorouridine and cisplatin in the treatment of advanced gastric cancer with primary foci. Cancer 72: 658-662, 1993.

19 Koizumi W, Narahara H, Hara T, Takagane A, Akiya T, Takagi M, Miyashita K, Nishizaki T, Kobayashi O, Takiyama W, Toh Y, Nagaie T, Takagi S, Yamamura Y, Yanaoka K, Orita H and Takeuchi M: S-1 plus cisplatin versus S-1 alone for first-line treatment of advanced gastric cancer (SPIRITS trial): a phase III trial. Lancet Oncol 9: 215-221, 2008.

20 Macdonald JS, Smalley SR, Benedetti J, Hundahl SA, Estes NC, Stemmermann GN, Haller DG, Ajani JA, Gunderson LL, Jessup JM and Martenson JA: Chemoradiotherapy after surgery compared with surgery alone for adenocarcinoma of the stomach or gastroesophageal junction. N Engl J Med 345: 725-730, 2001.
21 Ohkuwa M, Ohtsu A, Boku N, Yoshida S, Miyata Y, Shirao K, Shimada Y and Kurihara M: Long-term results for patients with unresectable gastric cancer who received chemotherapy in the Japan Clinical Oncology Group (JCOG) trials. Gastric Cancer 3: 145-150, 2000.

22 Nakajima T, Kinoshita T, Nashimoto A, Sairenji M, Yamaguchi T, Sakamoto J, Fujiya T, Inada T, Sasako M and Ohashi Y: Randomized controlled trial of adjuvant uracil-tegafur versus surgery alone for serosa-negative, locally advanced gastric cancer. Br J Surg 94: 1468-1476, 2007.

23 Japanese Gastric Cancer A: Japanese Classification of Gastric Carcinoma - 2nd English Edition. Gastric Cancer 1: 10-24, 1998.

24 Sakuramoto S, Sasako M, Yamaguchi T, Kinoshita T, Fujii M, Nashimoto A, Furukawa H, Nakajima T, Ohashi Y, Imamura H, Higashino M, Yamamura Y, Kurita A and Arai K: Adjuvant chemotherapy for gastric cancer with S-1, an oral fluoropyrimidine. N Engl J Med 357: 1810-1820, 2007.

25 Shirasaka T, Shimamato Y, Ohshimo H, Yamaguchi M, Kato T, Yonekura K and Fukushima M: Development of a novel form of an oral 5-fluorouracil derivative (S-1) directed to the potentiation of the tumor selective cytotoxicity of 5-fluorouracil by two biochemical modulators. Anticancer Drugs 7: 548-557, 1996.

26 Bang YJ, Kim YW, Yang HK, Chung HC, Park YK, Lee KH, Lee KW, Kim YH, Noh SI, Cho JY, Mok YJ, Kim YH, Ji J, Yeh TS, Button P, Sirzen F and Noh SH: Adjuvant capecitabine and oxaliplatin for gastric cancer after D2 gastrectomy (CLASSIC): a phase 3 open-label, randomised controlled trial. Lancet 379: 315-321, 2012.

27 Noh SH, Park SR, Yang HK, Chung HC, Chung IJ, Kim SW, Kim HH, Choi JH, Kim HK, Yu W, Lee JI, Shin DB, Ji J, Chen JS, Lim Y, Ha S and Bang YJ: Adjuvant capecitabine plus oxaliplatin for gastric cancer after D2 gastrectomy (CLASSIC): 5-year follow-up of an open-label, randomised phase 3 trial. Lancet Oncol 15: 1389-1396, 2014.
Received March 27, 2017

Revised April 16, 2017

Accepted April 19, 2017 